\title{
Hemiataxia With Ipsilateral Sensory Disturbance Due to a Pontine Infarction
}

\author{
Hiromasa Tsuda ${ }^{\mathrm{a}, \mathrm{b}}$, Tomoko Fujita ${ }^{\mathrm{a}}$
}

\begin{abstract}
A 77-year-old man with essential hypertension abruptly developed marked hemiataxia, and paresthesia and decreased vibration sensation in the left-sided upper and lower extremities. There were no other neurological abnormalities. Cranial diffusion-weighted magnetic resonance imaging demonstrated a localized infarction in the right-sided median zone of the middle pons. Cranial magnetic resonance angiography finding was normal. Under anti-platelet agent, he became asymptomatic within 5 days. Impairment of the descending corticopontine fiber and/or pontine nucleus causes contralateral hemiataxia. Involvement of the medial lemniscus induces paresthesia and disturbance of vibration sensation in the contralateral limbs. In our patient, not only the cerebro-ponto-cerebellar pathway but also the medial lemniscus might be damaged. Hemiataxia with ipsilateral sensory disturbance is commonly regarded as indicating sign of lateral thalamic lesion. However, we emphasize that hemiataxia with ipsilateral sensory disturbance rarely results from infarct lesion in the contralateral median zone of the middle pons.
\end{abstract}

Keywords: Corticopontine fiber; Magnetic resonance imaging; Medial lemniscus; Pons; Pontine nucleus

\section{Introduction}

Hemiataxia with ipsilateral sensory disturbance is commonly caused by lateral thalamic lesion [1-4]. Here, we report a very rare case of hemiataxia with ipsilateral sensory distur-

\footnotetext{
Manuscript accepted for publication January 24, 2014

${ }^{\text {a } D e p a r t m e n t ~ o f ~ N e u r o l o g y, ~ T o k y o ~ M e t r o p o l i t a n ~ H e a l t h ~ a n d ~ M e d i c a l ~}$ Corporation Toshima Hospital, 33-1, Sakaecho, Itabashi-ku, 173-0015 Tokyo, Japan

${ }^{\mathrm{b}}$ Corresponding author: Hiromasa Tsuda, Department of Neurology, Tokyo Metropolitan Health and Medical Corporation Toshima Hospital, 33-1, Sakaecho, Itabashi-ku, 173-0015 Tokyo, Japan. Email: hiromasa_tsuda@tokyo-hmt.jp
}

doi: http://dx.doi.org/10.14740/jmc1675w bance due to a pontine infarction.

\section{Case Report}

A 77-year-old man with essential hypertension abruptly complained of paresthesia in the left-sided upper and lower extremities in November 2013. Consciousness was alert. Blood pressure was $156 / 92 \mathrm{mmHg}$. The heart rate was $60 /$ min. General examination demonstrated no abnormalities. Cranial nerve impairment was not detected. In the upper extremities, Barre sign was negative. In the lower extremities, neither Barre sign nor Mingazzini sign was detected. Manual muscle testing on the extremities was all normal. Muscle tonus was normal in the extremities. Muscle atrophy and fasciculation were not observed. Deep tendon reflexes were all normal and pathological reflexes were not detected in the extremities. Paresthesia and decreased vibration sensation was observed in the left-sided upper and lower extremities. However, pain sensation, temperature sensation, topesthesia, joint sensation and combined sensation (two-point discrimination, graphesthesia, stereognosis and double simultaneous stimulation) were all normal. In left-sided upper extremity, dysmetria, decomposition of movement and intension tremor were observed in finger-nose test and nose-finger-nose test.

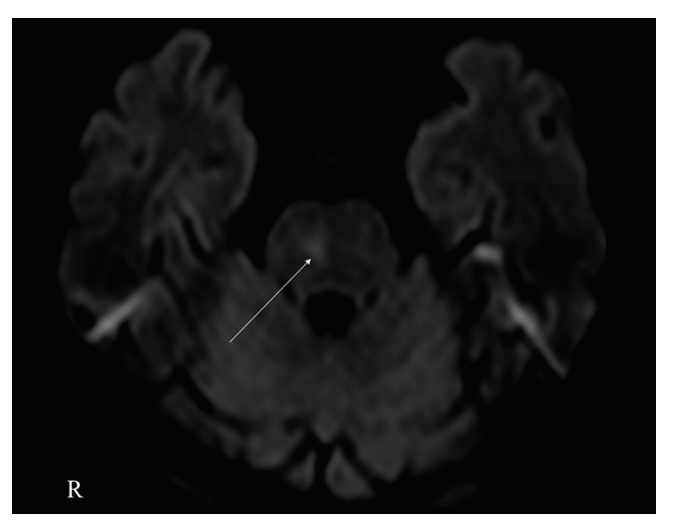

Figure 1. Cranial diffusion-weighted MRI demonstrated a localized infarction in the right-sided median zone of the middle pons (arrow). 
Hyperpronation test and hand pronation supination test were slightly slow in the left side. In heel-knee test and shin-tapping test, dysmetria and decomposition of movement were observed in the left-sided extremities. Truncal ataxia was not observed. There were no other neurological abnormalities. Laboratory examination was within normal ranges. Chest $\mathrm{X}$-ray finding was normal. Electrocardiogram demonstrated no abnormalities. Cranial diffusion-weighted magnetic resonance imaging (MRI) demonstrated a localized infarction in the right-sided median zone of the middle pons (Fig. 1). Cranial magnetic resonance angiography finding was normal. Under intravenous sodium ozagrel at $160 \mathrm{mg} /$ day (antiplatelet agent), he became asymptomatic within 5 days.

\section{Discussion}

Involvement of the medial lemniscus may induce paresthesia and disturbance of deep sensation in the contralateral limbs [5-10]. Kim et al [9] noted four cases of hemiataxia with ipsilateral sensory disturbance due to pontine stroke. However, the etiology of hemiataxia was not referred [9]. On the other hand, impairment of the cortico-ponto-cerebeller pathway may cause hemiataxia [11-13]. To our knowledge, there has been only one reported case of isolated hemiataxia due to contralateral pontine infarction [11]. Schmahmann et al [13] stated that upper extremity ataxia might be mostly correlated with damage to the ventral pontine nucleus, and lower extremity ataxia might be induced by impairment to the more lateral region than those for the arm in the middle and caudal pons.

In our patient, despite normal position sense, marked hemiataxia was observed. Therefore, based on neurological symptoms and cranial MRI finding, in addition to the medial lemniscus, the descending corticopontine fiber and/or pontine nucleus in the cortico-ponto-cerebeller pathway might be involved.

In conclusion, we emphasize that hemiataxia with ipsilateral sensory disturbance rarely results from infarction in the contralateral median zone of the middle pons.

\section{Conflicts of Interest}

The authors declare no conflict of interest.

\section{Grant Support}

None.

\section{References}

1. Melo TP, Bogousslavsky J. Hemiataxia-hypesthesia: a thalamic stroke syndrome. J Neurol Neurosurg Psychiatry. 1992;55(7):581-584.

2. Melo TP, Bogousslavsky J, Moulin T, Nader J, Regli F. Thalamic ataxia. J Neurol. 1992;239(6):331-337.

3. Solomon DH, Barohn RJ, Bazan C, Grissom J. The thalamic ataxia syndrome. Neurology. 1994;44(5):810-814.

4. Dobato JL, Villanueva JA, Gimenez-Roldan S. Sensory ataxic hemiparesis in thalamic hemorrhage. Stroke. 1990;21(12):1749-1753.

5. Hommel M, Besson G, Pollak P, Borgel F, Le Bas JF, Perret J. Pure sensory stroke due to a pontine lacune. Stroke. 1989;20(3):406-408.

6. Kim JS. Pure sensory stroke. Clinical-radiological correlates of 21 cases. Stroke. 1992;23(7):983-987.

7. Kim JS, Jo KD. Pure lemniscal sensory deficit caused by pontine hemorrhage. Stroke. 1992;23(2):300-301.

8. Shintani S, Tsuruoka S, Shiigai T. Pure sensory stroke caused by a pontine infarct. Clinical, radiological, and physiological features in four patients. Stroke. 1994;25(7):1512-1515.

9. Kim JS, Bae YH. Pure or predominant sensory stroke due to brain stem lesion. Stroke. 1997;28(9):1761-1764.

10. Numao A, Suzuki K, Iwanami H, Hirata K. Pure sensory stroke due to pontine tegmentum infarction. Intern Med. 2011;50(17):1865.

11. Marx JJ, Iannetti GD, Thomke F, Fitzek S, Galeotti F, Truini A, Stoeter P, et al. Topodiagnostic implications of hemiataxia: an MRI-based brainstem mapping analysis. Neuroimage. 2008;39(4):1625-1632.

12. Cicirata F, Serapide MF, Parenti R, Panto MR, Zappala A, Nicotra A, Cicero D. The basilar pontine nuclei and the nucleus reticularis tegmenti pontis subserve distinct cerebrocerebellar pathways. Prog Brain Res. 2005; 148:259-282.

13. Schmahmann JD, Ko R, MacMore J. The human basis pontis: motor syndromes and topographic organization. Brain. 2004;127(Pt 6):1269-1291. 